\title{
Sergio Raimondi: el arte de la sólida erosión
}

\section{Sergio Raimondi: the art of solid erosion}

\author{
MARIANA DI CIÓ \\ Université Paris 3 - Sorbonne-Nouvelle \\ mariana.di-cio@sorbonne-nouvelle.fr
}

En su poemario Poesía civil (2001), Sergio Raimondi plantea una nueva articulación entre lo público y lo privado: a través de una mirada detallista y doméstica de lo social, transforma las circunstancias más banales o microscópicas de la vida cotidiana en pequeńas iluminaciones. La propuesta consiste en analizar el modo en que Raimondi se sirve tanto de la cartografía urbana (vías de ferrocarril, fábricas, muros desgastados...) como de las inscripciones de los espacios públicos de una Bahía Blanca que parece como detenida en el tiempo (restos de carteles, afiches publicitarios, carnets de biblioteca...) para tejer un espacio íntimo en textos que enlazan estos "lugares comunes" con lecturas eruditas. Se intentará desentrañar el modo en que, a través de una mirada personal, Raimondi "lee" una envejecida trama urbana para proponer simultáneamente una mirada retrospectiva sobre el avance de la urbanización y una mirada crítica sobre el presente de su escritura y construye, a través de las huellas y residuos del pasado y de las capas del tejido urbano que esta misma mirada va revelando, una poesía "de resistencia"; una "poesía civil" que funciona a la vez como archivo de la memoria colectiva y como potente denuncia de los estragos de la modernidad postindustrial, en particular del neoliberalismo económico de los años noventa.

Palabras clave: Sergio Raimondi, poesía argentina, espacio público, restos, deshechos.

Sergio Raimondi's Civil poetry (2001) proposes a new articulation of the public/ private distinction: the attention paid to domestic situations fosters a way of looking at social phenomena that transforms rather ordinary or trivial circumstances into small illuminations. This article intends to analyze the way in which Raimondi uses both urban cartography (railroad lines, warehouses and factories, wornout walls...) and inscriptions that can be still found in public spaces of a frozen-in-time Bahia Blanca (remainders of street signs, advertisements, library cards...) to weave an intimate space in texts that entwine these "common places" with more erudite or scholar readings. The idea is to fathom the way in which Raimondi "reads", in his own personal way, an aged urban scene while proposing a

\footnotetext{
* Una primera versión de este texto fue presentada en el marco del II Simposio de la sección de Estudios del Cono Sur (LASA: Latin American Studies Association): “Modernidades, (in)dependencias, (neo)colonialismos", llevado a cabo en Montevideo del 19 al 22 de julio de 2017. Agradezco a Mariano Sverdloff y a Santiago Venturini sus lecturas y sugerencias.
} 
retrospective regard on the whole progress of urbanization and, at the same time, suggests a critical regard on the present of enunciation. It is through the deciphering of these traces and residues from the past, as well as the unraveling of multiple layers of urban cartography, that his poetry reveals itself as a means of resistance, inasmuch as his "civil poetry" functions both as an archive for collective memory and as a powerful protest against the ravages of post-industrial society, in particular economic neoliberalism policies in place during the 1990's.

Key words: Sergio Raimondi, Argentine poetry, public space, remains, waste.

\section{SERGIO RAIMONDI: EL ARTE DE LA SÓLIDA EROSIÓN}

\section{los restos de una era que ni vos ni yo llegamos a conocer, ruinas de fierro vidrio y ladrillo del aserradero, virutas y aserrin en el piso arrasado Daniel García Helder, (Tomas para un documental)}

Pedazos de chapa oxidada, pisos de portland, torres de alta tensión, "llantas usadas, latas, redes, / maderas, alambres" (Raimondi 2001: 65); lejos de ser bucólicos, los paisajes de Poesía civil (2001) son descarnados, deshumanizados, casi ilegibles como tales. Con un tono acerado, pero engañosamente aséptico, Sergio Raimondi recorre el puerto de Ingeniero White y la cartografía urbana de una Bahía Blanca que parece como detenida en el tiempo y hasta desertada; "un paisaje de trabajo sin trabajo" (Jurovietzky 2014: 934); "una celebración del paisaje industrial" (Dobry 2016: 106). El poemario se abre con una sección llamada "De la lengua y el arte como capital", que anuncia el materialismo que animará todo el poemario. El primer texto es "Ante un ejemplar de Defense of poetry con el sello 'Pacific Railway Library, B. Bca., n 815 (to be returned within 14 days)'”, un poema que, al hacer visibles los nuevos modelos económicos y el impacto de estos en la circulación del capital, refuta y da una vuelta de tuerca suplementaria al anticapitalismo romántico de Shelley ("que poesía y principio de propiedad / dos fuerzas son que se repelen", Raimondi 2001: 11); un gesto que, para Ana Porrúa, contribuye a "rearmar un territorio" (2013), y que para los compiladores de La tendencia materialista representa, en cierta medida, un cierre en relación con algunas de las propuestas de la llamada "poesía de los 90" (Kesselman, Mazzoni, Selci, 2012: 19-20) ${ }^{1}$.

La propuesta es estudiar el modo en que, gracias un enfoque microscópico y/o doméstico, Raimondi pone de relieve la desarticulación, el desgaste, la erosión de buena parte del entramado social, a tal punto que podríamos decir -es la hipótesis- que Poesía civil constituye una suerte de archivo o reservorio de prácticas, de atmósferas, de vivencias y hasta de vestigios de discursos que se presentan como amenazados o ya en vías de desaparición, incluyendo el uso de versos de arte mayor y de estructuras que resultan casi anacrónicas,

${ }^{1}$ Acerca de la inserción (o no) de Raimondi en la llamada “generación de los noventa”, ver Berger 2016: 312. 
especialmente si se las lee junto a aquellas que proponen la mayor parte de los poetas de los 90. En ese sentido, no es casual que, para describir y al mismo tiempo "leer" la desvencijada trama comunitaria, Raimondi se sirva del pasado como principio constructivo, ya sea para reciclarlo o reorganizarlo, o para generar un elocuente contraste con el presente. De ahí que la mirada retrospectiva sobre el avance masivo de la industrialización en un contexto de creciente instalación y afianzamiento en el país de empresas transnacionales implique, por un lado, la relectura de los discursos fundacionales pero también de aquellos que sustentan o acompañan el giro liberal en la economía, que Raimondi acompaña de una mirada crítica y por momentos hasta premonitoria (recordemos que el libro se publica en octubre de 2001) acerca del impacto que este proceso pretendidamente renovador tiene o tendrá en el presente de la escritura ${ }^{2}$.

Desde esta perspectiva, y según una lógica análoga al paradigma de inferencias indiciales desarrollado por Carlo Ginzburg en el marco de la microhistoria, donde lo borrado, lo descartado, lo residual se transforma en rastro, huella o evidencia de acontecimientos o de fenómenos del pasado que en cualquier otro tratamiento de las fuentes pasarían inadvertidos, consideraré en un primer momento el modo en que, valiéndose de una atípica voz en tercera persona ${ }^{3}$, Raimondi introduce o reintroduce en la poesía aquello que se quiere esconder o empujar hacia fuera de la ciudad, y que resulta, para ciertos cánones estéticos, deliberadamente antipoético. Para ello, repasaré rápidamente el modo en que las páginas de Poesía civil materializan los desechos y la basura, según una dinámica en la que los cuerpos fluctúan entre la deshumanización y la cabal manifestación de su corporalidad. Los gestos más banales de la vida cotidiana (cocinar, comer, dormir la siesta) se convierten así no sólo en una suerte de archivo de un tiempo menos despiadado -restos de una época que aún no se ha agotado del todo y a la que por lo tanto todavía se puede aspirar- sino que también funcionan como escenas de fuerte contenido político que ponen de manifiesto las dinámicas económicas que atraviesan cada uno de nuestros gestos cotidianos y que, como lo sugieren Kesselman, Mazzoni y Selci, en cierta medida le permiten postular "una teoría de la literatura nacional completamente económica" (2012: 293).

Pero hay también, en esta poesía civil, otro tipo de restos -o de rastros- que han sobrevivido al paso del tiempo, y que Raimondi recupera para hacer dialogar con lecturas eruditas - a veces poéticas, pero no siempre. Estos discursos o fragmentos de discursos que remiten a un pasado remoto y que por lo general resultan anacrónicos en sí mismos, suelen

\footnotetext{
2 "Escritos en su gran mayoría entre fines de 1999 y mediados de 2001, estos poemas son contemporáneos de las modificaciones económicas, políticas y sociales consolidadas durante las dos presidencias consecutivas de Carlos Menem y la hegemonía de la convertibilidad" (contratapa de la 2da edición, 2010).

${ }^{3}$ Marcelo Díaz señala los variados usos de formas impersonales, la peculiar sintaxis, la falta de énfasis y el modo en que el autor borra su voz como opinión o juicio personal "(como el plomero o el jardinero que ofrecen el contrapunto a la figura del poeta 'romántico')" como elementos que contribuyen a que el poema aparezca "como construcción de un mecanismo que procesa discursos, que hace convivir voces coloquiales [...] con el despliegue minucioso de datos y porcentajes, lírica y descripciones, frases cercanas a un estilo de informe profesional o directamente informativo, transportadas en el soporte de un verso que tiende a la regularidad [...] y que a su vez da lugar a un amplio abanico de matices" (Díaz 2002).
} 
estar apuntalados por referencias cotidianas o, si se quiere, más banales, y por ello mismo consolidan algo así como un archivo o reservorio de la memoria colectiva, que sirve de tela de fondo ideológica, de sustento ontológico para todo el poemario. En un segundo momento, entonces, analizaré el modo en que estas palabras como venidas de otro tiempo coexisten con la geografía cuasi apocalíptica del presente; una combinación que, en su tremendo desfasaje, genera algo parecido a un diálogo de muertos, un intercambio fantasmagórico que refuerza la aridez que impregna todo el poemario.

Porque desde su seca rispidez, Poesía civil parece poner de relieve la lenta pero sólida erosión (2001: 74) de lo real; parece intentar salvaguardar, aunque más no sea a través de la palabra, aquello que ya se ha perdido para siempre. Y es precisamente gracias a este vacío que se construye con palabras que el poemario todo se erige como potente denuncia de los estragos de la modernidad postindustrial, y en particular del neoliberalismo de los ańos noventa. Por otra parte, esta particular forma de archivo que se esconde detrás de los textos de este poemario parece funcionar también como una suerte de escudo protector frente a la desmemoria de una época que, en pos del progreso, decide darle la espalda al pasado ${ }^{4}$; remedo, tal vez, del archivo oral del Museo del Puerto de Ingeniero White que Raimondi dirigió entre 1987 y 2007, cuyo objetivo es, precisamente, interrogar las articulaciones entre la vida cotidiana y las narrativas de la producción local, nacional y mundial.

\section{EL RETORNO DE LO REPRIMIDO}

Así como, a principios de los años sesenta, Antonio Berni empieza a utilizar los restos de la sociedad de consumo para plasmar en texturas la áspera realidad de Juanito Laguna, también Raimondi se propone, varias décadas más tarde, acercar arte y política. Recurre, para ello, al ensamblaje de la literatura con la industria y la técnica, a través de sorprendentes comparaciones entre la poesía y los mecanismos de producción:

Por eso es curioso que la métrica, considerada por el poeta como el elemento similar y constante que organiza todo un nuevo modo de componer actúe tal como el regulador que por ese tiempo Watt introdujo en la máquina a vapor para darle velocidad de funcionamiento estable y promover todas las automatizaciones que habrían de venir

(Raimondi 2001: 13)5.

\footnotetext{
4 "El presente es un dominio absolutamente necesario para un museo", escribirá Raimondi en un documento interno del Museo del Puerto de Ingeniero White (citado en Porrúa 2002).

${ }^{5}$ Hay aquí, seguramente, también rastros de la influencia de Francis Ponge: "La función del artista es [...] muy clara: debe abrir un taller y reparar el mundo tal como le llega, por fragmentos. Y que no por ello se considere un mago. Es sólo un mecánico" (1952: 6).
} 
Si la mirada escéptica frente a la industrialización y en particular frente a la contaminación y acumulación de desechos está también presente en algunos otros artistas de la época -piénsese, por ejemplo, en la fotografía "Sireno del Río de la Plata", de Marcos López (2002) - es interesante notar cómo, a diferencia de la irónica puesta en escena de López, en que un escultural "sireno" intenta conquistar al espectador desde las mancilladas costas del Riachuelo, Raimondi insiste más en la maquinaria, y en la dinámica de la mecanicidad, que en los cuerpos mismos: "[...] Poesía y ferretería, destornillador / y vocal, metonimia a 220, en morsa la metáfora / a ser por el toc ajustada del martillo" (Raimondi 2001: 55). Más aún, diría incluso que la deshumanización se hace patente a través de cuerpos que se presentan cosificados, o filtrados por máscaras que ocultan sus rasgos distintivos, al punto de asemejarse a una naturaleza muerta, tal como se lee en "Paisaje de Induclor con uno o dos operarios":

Ahora el operario limpia el sistema
con ácido. [...]
No se le ve la cara. Lo que se le ve
es una máscara con carbón activado
que filtra los vapores del metal.
Tampoco al otro se le ve la cara, se le ve
una máscara igual, pero su cuerpo
es más voluminoso y los zapatos difieren

(Raimondi 2001: 23).

También en "Oración pesquera con digresión" los operarios parecen agostarse detrás de la escafandra supuestamente protectora: "Toscas mangas sobre los brazos, gruesas mangas / de goma para alejar el ácido de las aguas vivas / y plomo en los pies sobre cubierta [...]" (Raimondi 2001: 63). Presentada casi como un rasgo anecdótico o incluso una digresión, la brutalidad con que se presenta la corrosión permite, al igual que en el Diario del fumigador de guardia de Arnaldo Calveyra, evocar de manera oblicua la presencia siempre acechante de la muerte para el trabajador que pone en jaque su salud y se arriesga a la respiración contaminada.

Pero la intoxicación no siempre es motivada por la industria: también las hay, más banales, pero igualmente devastadoras, con alcohol barato y a la vista de centenares de pasantes que eligen no ver al linyera de carne y hueso, o que lo convierten en marmórea estatua -que es otra forma de no ver-, como leemos en "Sileno en la estación ferroviaria":

Acostado de lado, con un codo incómodo apoyado en el cemento y la cabeza tirada hacia atrás, duerme. Rodillas dobladas, pies contra el culo, al aire la panza enorme, boca abierta al cielo, chata nariz. Esto es obra de dos o tres tetra-brik. Si fuera de mármol estaría expuesto en un museo de Roma, Londres o París 
como ejemplo de arte helenístico.

Y no le molestarían las moscas

(Raimondi 2001: 19).

Junto con la estetización desplazada y la crítica mordaz, la descripción sobria y a la vez casi naturalista del indigente reintroduce, en el espacio colectivo y cotidianamente transitado de la estación de trenes, aquellos cuerpos que molestan, que son invisibilizados o marginados de las sociedades, aun cuando forman parte del paisaje diario o, literalmente, de los "lugares comunes" que todos atravesamos. Y si las páginas de Poesía civil transitan casi con naturalidad desde el zaparrastroso que atrae a las moscas en la estación hasta la cocina y sus desperdicios, es tal vez porque, al igual que el paisaje implacablemente industrial, estas esferas materializan de manera inequívoca las desigualdades y las tensiones, el exceso y el defecto, el costo y el beneficio; todo lo que alimenta, en definitiva, la dinámica producción/ consumo.

Frente al avance de las multinacionales, que al procesar los alimentos con la mano en el bolsillo y la mirada en puesta en "las estadísticas de embarque" (Raimondi 2010: 74) prolongan, en cierta medida, la política agraria desarrollada por la generación del 80 (el modelo agroexportador), Raimondi recurre a figuras como Pound, que rescata la antigua poesía para ponerla al servicio de una concepción moderna, conceptual y al mismo tiempo fragmentaria, y que le permiten hacer dialogar industria y literatura con una pizca de humor ("Cargill \& Pound"; "Shklovski en diálogo con los productores de papa") e insistir en los permanentes desplazamientos entre lo local, lo nacional y lo mundial. Muchas de las microescenas narrativas que componen el poemario se articulan, precisamente, en torno a la alimentación, o a la preparación de los alimentos: "Hoy cocina Matsuo Basho", "La dieta de Dante", "Para hacer una torta sin leche"; la segunda sección se llama, incluso, "La vianda bajo la lupa", quizás como una forma de reivindicar, justamente, esa articulación entre el mundo de la vida cotidiana y el mundo de la producción, y de mostrar el impacto de ciertas políticas económicas en la vida diaria de hombres y mujeres reales: "Hablar de literatura es hablar de economía; hablar de poesía moderna supone hablar de economía capitalista”, insisten Kesselman, Mazzoni y Selci (2012: 293).

Pero los versos de Raimondi no siempre se inscriben en la dinámica circular de la reutilización o del reciclaje; también se articulan, por momentos, a partir de un vaivén en donde el fluir de las olas que chocan contra el muelle se vuelve espejo del incesante vaivén de los flujos económicos, o a partir de la acumulación excesiva, materializada en los desechos que arrastra la corriente de resaca. Es el caso de "Qué es el mar", donde para responder a la pregunta inicial, el paisaje se declina en una ristra de enumeraciones caóticas que se desaguan en un único y simple deíctico final, "eso", que condensa el despilfarro y los excesos ambientales de un capitalismo desmadrado:

El barrido de una red de arrastre a lo largo del lecho, mallas de apertura en máxima, en el tanque setecientos mil 
litros de gas-oil, en la bodega bolsas de papa y cebolla, jornadas de treinta y cinco horas, sueño de cuatro, café, acuerdos pactados en las oficinas de Bruselas, crecimiento del calamar illex en relación con la temperatura del agua

(Raimondi 2001: 28).

Algo similar ocurre en el poema llamado "Lo que dejó de ser con la resolución del Servicio Nacional de Sanidad Animal (SENASA) del 4 de abril de 1997 concerniente a la probibición de realizar el pelado de camarones en domicilios particulares", donde la descripción de un ritual cotidiano -el pelado manual de camarones- engrandece el oficio hasta hacerle cobrar matices casi épicos, que contrastan con el modo en que los caparazones inútiles van cayendo en la fuente de plástico naranja hasta convertirse, como la jubilación o los granos de la abundancia que devoran las ávidas gallinas, en espuma tenue, vaga huella de lo que aquello alguna vez fue. En cierta medida, al desgranar, mediante la enumeración, cada uno de los gestos del pelador, Raimondi dirige nuestra mirada hacia el oficio mismo; un oficio que, en su mecánica repetición, se va deshaciendo y disolviendo en gestos anodinos, hasta llegar a resultar anacrónico y prácticamente obsoleto:

Sobre la mesa de la cocina de la casa frente a la Usina: una fuente grande con cientos de camarones, un bol naranja donde va cayendo la carne limpia, un plato playo donde van cayendo la caparazón y las antenas, un plato sopero de loza blanca con agua casi blanca donde el pelador se lava los dedos para recibir el mate que le ofrece su mujer. Dejó el cajón el camión a eso de las nueve, y volverá el perro a sentir el motor a eso de las cinco de la tarde. Pero acá creen que van a tener lista toda la pila para las dos, así se come, tranquilamente y con la radio, una hervida de verduras. Nada demasiado suculento, ya que el estómago lleva cuenta de la irregular picada durante la labor. Y después la siesta para Pedro Quinter, quien verá despertarse desde el patio, entre llantas usadas, latas, redes, maderas, alambres, lavarropas y pedazos de la carrocería de algún auto, cuando levante la vista de los picos afanosos de las gallinas que se abalanzan sobre el cereal que deja caer como un dios de la abundancia al abrir su mano, a Norma Barassi que vuelve de la cocina del Comedor de Jubilados del Barrio Saladero

(Raimondi 2001: 65). 


\section{Persiste la letra en el hierro escrita}

No deja de llamar la atención, en ese contexto de rescate y recuperación, la frecuencia con la que aparecen escrituras, o huellas de escrituras, que podríamos asimilar a lo que el oulipiano François Le Lionnais llama el "tercer sector": palabras que, sin ser literatura ni paraliteratura, están escritas pero no se venden (aunque a veces ayuden a vender): graffiti, carteles con ordenanzas públicas, recetas de cocina, discursos, informes técnicos, letreros luminosos o no y anotaciones de todo tipo, generalmente inclasificables y sobre todo inclasificadas, que muchas veces se hacen visibles solo desde el espacio paratextual del título, aunque marcan la clave de lectura de todo el poema.

Las historias mínimas, cotidianas, absolutamente banales, que Raimondi presenta bajo su lupa se erigen así, a través de esta sutil revalorización de la materialidad de la palabra, como pequeños actos de resistencia, como un elogio y un intento de recuperación de lo artesanal y lo casero, de todo aquel saber impalpable que si nadie pusiera por escrito se perdería para siempre y que, otra vez, se emparenta también con el trabajo de archivo oral del Museo del Puerto de Ingeniero White: "El resto se sabe: enmantecar el molde, enharinarlo / y horno. Titi Trujillo le echa un chorrito de vino / oporto. Titina Lancioni a veces licor de café o esencia / de vainilla. Otros le ponen trozos de manzana, / pasas de uva, chocolate o ciruela. Eso va en gustos, / en las ganas de inventar, en lo que se tenga a mano" (Raimondi 2001: 66). Frente a la homogeneización del producto industrial, la recuperación de una receta "Para hacer una torta sin leche" y el elogio de la variante, del azar, del pequeño compendio de economía doméstica que se esconde detrás de aquel que cocina con "lo que se tenga a mano", la contingencia del producto casero como resistencia. Frente al avance de la poesía deliberadamente superficial de la muchos de los poetas de los 90, Raimondi propone una vuelta al verso ritmado y a la estructura lógica de las letras clásicas ${ }^{6}$ para materializar su percepción política de la realidad.

A menudo desplazados, estos detritus textuales o "actos de lenguaje restantes" crean una suerte de código dentro del código, que con frecuencia remite a inscripciones que competen al espacio público: pueden aparecer en la ficha en inglés de una biblioteca ferroviaria; en leyes, disposiciones y ordenanzas municipales con las que dialoga la voz poética; en referencias literarias al Romanticismo inglés o en aforismos y sentencias que sintetizan el pensamiento de la generación del 80; pero también en graffiti o carteles con

\footnotetext{
6 "En la medida en que el desafío de Raimondi consiste en reducir las imágenes a los procesos, su estilo adquiere necesariamente un tono explicativo o ensayístico. Por esta razón la prosodia del libro suele ayudarse de palabras, vueltas y fórmulas expositivas propias de los géneros argumentativos clásicos. [...] Este tipo de expresión resulta inusual con respecto a casi toda la poesía de los 90; Poesía civil retoma, en este aspecto, los procedimientos reflexivos de la poesía de Daniel García Helder” (Kesselman, Mazzoni, Selci 2012: 292-293).

${ }^{7}$ Cabe recordar que, en su juventud, Raimondi formó parte del grupo de los mateístas, un grupo poético/político activo en Bahía Blanca a fines de los años ochenta que, mediante pintadas y revistas murales, buscaba intervenir en la esfera social y "poner la poesía en la calle". He desarrollado este aspecto en 2017: 309-326.
} 
consignas anacrónicas que, pese a que parecen anticipar el triste e inminente crecimiento exponencial de los cartoneros, se emparentan más al "[t] rote hueco de los jamelgos que pasan y nos emocionan sin razón” de los "Caballos en la vía pública” de Girondo a principios de los ańos veinte que a los albores del siglo XXI:

Una reglamentación referida a los horarios en los que es lícito que un decimonónico caballo haga resonar sus herrajes en la vía pública, eso es el poder. Por eso apenas la yunta cansada del sol sobre la loma asoma arriban los carros al galpón trayendo en sus cajas botellas, cartones y metales recolectados a lo largo de una noche cualquiera; aquellos capaces de distinguir la rentabilidad en lo que el resto de los vecinos considera inútil sentados van sobre un tablón con las riendas en la mano, y por las calles de la ciudad deambulan en concordancia a un tranco cansino que no sabe de la urgencia del camión de la empresa de limpieza al que, democrático, todo le da igual.

Los animales conocen su recorrido de memoria. Salvo en una jornada en la que se ha reunido más de lo habitual y gravoso es el peso de la carga, no hace falta recordarles la existencia del alma

(Raimondi 2001: 67).

Otras veces, las inscripciones aparecen borrosas, apenas visibles bajo capas de ladrillo y de cal, aunque en ocasiones la ilegilibilidad no radica tanto en la materialidad como en el contenido mismo. En las vías del tren, en los muros desgastados, en las fábricas, en un ejemplar de Defense of poetry de la ferroviaria biblioteca Pacific Railway Library de Bahía Blanca que viene con instrucciones en inglés o en un descaminado imperativo que se alcanza a leer bajo las cenizas; el pasado ferroviario y portuario de la ciudad se materializa y se hace visible a través de estas capas de "civilización”: "Abajo, sobre lo rojo, hierro: 'Es prohibido / transitar por las vías'. Los ingleses / armaron sus frases desde los cimientos / con voluntad igual a la de sus arquitecturas: / fundacionales y con vocación de eternidad" (Raimondi 2001: 12).

Sin embargo, en esos vestigios de vida que sobreviven de manera fragmentaria y que Raimondi rescata, se vislumbra, a veces, un pasado todavía más remoto. Porque a las raíces anglo ${ }^{8}$ de la compañía F. C. Sud, que representan, como el propio poeta subraya en el

\footnotetext{
${ }^{8}$ Curiosamente, también estas referencias al pasado ferroviario británico aparecen asociadas a la sensorialidad e incluso bajo el signo de la alimentación, como se advierte en "Modificación en la alimentación de las locomotoras fabricadas en Europa”, donde se evoca “el reconocido sabor del carbón Cardiff” (2001: 106).
} 
prólogo a la segunda edición, la "máxima evidencia local del proyecto de la clase dirigente de la generación del 80" (Raimondi 2010: 11), Raimondi le agrega, le sobreimprime, falsas raíces latinas. De este modo acerca, aunque más no sea en el deseo, el presente industrializado y neoliberal del tiempo de la escritura a los ideales humanistas de un pasado áureo, sintetizados en el cangrejo y la mariposa del emblema augusto "Festina lente" ("Apresúrate despacio") que figura en la tapa de la primera edición (Vox). Además de dialogar con el pasado áureo y con la actividad pesquera del puerto de Ingeniero White, la presencia del emblema en la portada de la primera edición de Poesía civil anuncia también una magnífica puesta en abismo, que se materializará en la sección "Hay que dilapidar la herencia en gastos superfluos / Loa al cangrejo" y, de manera más concreta, en el poema "Héctor Ciocchini observa dos veces un mismo libro de estampas", en que Raimondi homenajea a Ciocchini destacado humanista de la Universidad Nacional del Sur que parece insuflar muchos de los versos del poemario y que también recurre al emblema "Festina lente" para ilustrar la tapa de su libro Los trabajos de Anfión (1969).

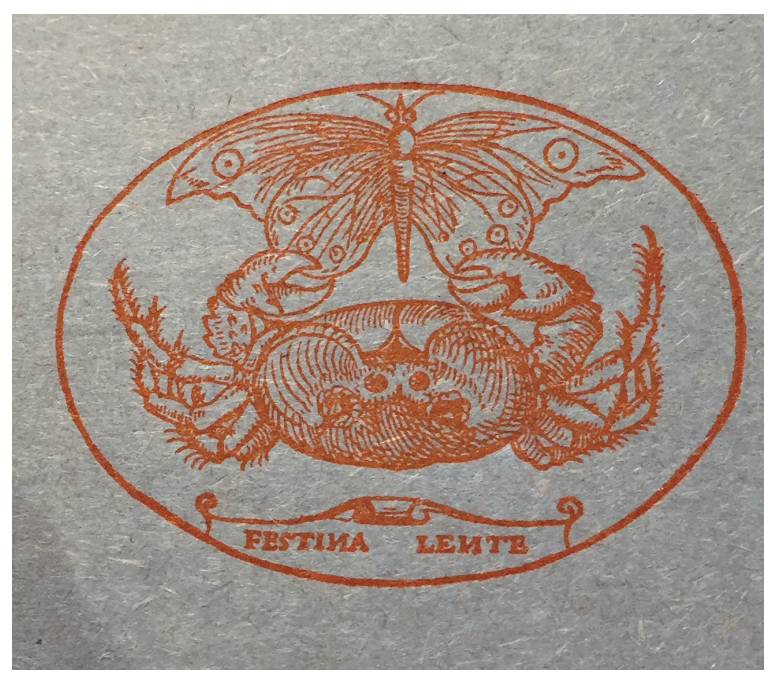

Figura 1. Emblema de Gabrielle Simeoni y Paolo Giovio, tomado de su obra Le Sententiose Imprese (Lyone, 1592), reproducido en la portada de Los trabajos de Anfión de Héctor Ciocchini (Bahía Blanca, Cuadernos del Sur, Instituto de Humanidades, Universidad Nacional del Sur, 1969).

Así también, por ejemplo, el mismo Pedro Quinter que, entre dos mates que le alcanzaba su mujer, pelaba camarones en la mesa de su cocina se condensa, apenas unas páginas más tarde, en parcas iniciales: "Lo que me dijeron, en su latín, las chapas, maderas, y fierros del patio de P.Q" (68), en lo que parece ser un recorte, y una parodia, de la parte central 
del célebre acrónimo $\mathrm{SPQR}^{9}$, que aun hoy persiste en las inscripciones y los monumentos y las calles de Roma como marca de su soberanía.

Lejos del gesto nostálgico, Raimondi se sirve de la materialidad de la letra, y de los residuos de cierta cultura letrada para proponer una mirada crítica sobre el progreso y la llamada "civilización" - un rasgo que será, por otra parte, una de las constantes a lo largo de todo el poemario. ${ }^{10}$ Es así, me parece, como debe leerse un texto que no por casualidad se llama "Civitas y humanitas", donde inmediatamente después de citar la definición de bumanitas ${ }^{l I}$ que da Cicerón en La cosa pública (De re publica), recurre a la siguiente boutade:

Por entre las columnatas algo griegas de la UNS descendieron esos hombres íntegramente formados, conocedores del obligado servicio de la literatura para la moral y la virtud y de su fruto inequívoco en beneficio del bien común: eruditio libero digna. Esta es su ciudad. Pasamos ahora frente a una pared que exhibe el grafito C.V.M. Me lleva horas explicar que no se trata de la preposición latina sino de la sigla del Club Villa Mitre, cuyo equipo de fútbol milita por el momento en el campeonato de la B Nacional

(Raimondi 2001: 72).

\section{LOA AL CANGREJO, O MARCHA ATRÁS Y PRECARIAS CONCLUSIONES}

A diferencia de la memoria de Funes, que recoge y registra indiscriminadamente todas las experiencias al punto de conformar, finalmente, un "vaciadero de basuras", Raimondi propone para su "archivo" una mirada mucho más selectiva, concentrada en la decoloración de fronteras entre lo público y lo privado; en la mercantilización del arte y de la literatura - a los que deliberadamente califica de "cuestiones menores"- pero también en la crítica a la sociedad neoliberal; en la reivindicación, o la rehabilitación, aunque más no sea por contraste, de lo artesanal, de lo local, de lo comunitario que, en última instancia, es también un modo de reivindicar la poesía como trabajo, como actividad civil.

Como el cangrejo que con sus pinzas intenta detener a la mariposa, Raimondi obliga al lector a detenerse, e incluso a retroceder en el tiempo, para poder pensar mejor

\footnotetext{
9 SPQR: (Senatus Populusque Romanus) apareció por primera vez en inscripciones en la última etapa de la República, del año 80 a. C. en adelante.

${ }^{10}$ En ese sentido, tal vez no sea casual la reiterada presencia de Sarmiento, en particular en lo que atañe a la polémica que mantuvo con Andrés Bello, en las páginas de Poesía civil.

11 "Aunque el término hombre es aplicado a todos, / pertenece propiamente sólo a aquellos que por medio / de las disciplinas liberales están convenientemente /educados para la formación humana (humanitas)" / (Cic. De rep., 1, 17, 28, tr. de Antonio Camarero). (72)
} 
el presente, a partir de este particular archivo compuesto de micro-escenas que él mismo definirá, en el prólogo a la segunda edición, como "momentos de una narrativa mayor y polémica: la de los modelos de producción” (Raimondi 2010: 12). Testimonios mudos de la realidad económica y cultural que se apropió del país durante la década del 90, al instalar la política - y la periferia - en el centro de Poesía civil, los poemas de Raimondi no solo recuperan restos simbólicos de una realidad que se está escurriendo - esos restos que, precisamente, "resisten" al avance despiadado del modelo agroexportador- sino que también construyen, frente al avance y al acecho del neoliberalismo, un verdadero acto de resistencia, un verdadero acto de poesía civil.

\section{Obras CITADAS}

Aguirre, Osvaldo. 2014. La poesia en estado de pregunta, Buenos Aires, Gog y Magog.

Berger, Timo. 2016. "De la calabaza a los contenedores: la poesía de Sergio Raimondi y la cuestión de la traducción”. En Ette, Otmar \& Julio Prieto. Eds. Poéticas del presente. Perspectivas críticas sobre poesía hispánica contemporánea, Madrid / Frankfurt. 311326.

Díaz, Marcelo. 2002. "El paladar de los comensales", Bazar Americano, diciembre 2001marzo 2002. http://www.bazaramericano.com/buscador.php?cod=173\&tabla=resen as\&que $=\mathrm{d} \% \mathrm{C} 3 \% \mathrm{ADaz}$ (consultado el 04/10/2018).

Di Ció, Mariana. 2017. "Contre les murs: la poésie civile de Sergio Raimondi", Les Lettres romanes, 71 (3-4): 309-326.

Dobry, Edgardo. 2016. "Volver a los XIX: acerca de lo contemporáneo en la poesía”. En Ette, Otmar \& Julio Prieto. Eds. Poéticas del presente. Perspectivas críticas sobre poesía hispánica contemporánea, Madrid / Frankfurt. 101-112.

García Helder, Daniel. 2007. "Aspectos materialistas en la poesía argentina”. En Delgado \& Julio Premat. Eds. Movimiento y nominación. Notas sobre la poesía argentina contemporánea, Cabiers de LI.RI.CO. Littératures contemporaines du Río de la Plata n 3.131 148. URL : http://journals.openedition.org/lirico/780 ; DOI : 10.4000/lirico.780

Ginzburg, Carlo. 2010 [1986]. "Traces". En: Mythes, emblèmes, traces. Morphologie et histoire [1986], nouvelle édition augmentée, Paris: Verdier/Poche. 218-294.

Girondo, Oliverio. 1998 [1968]. Obras I. Poesía, prólogo de Enrique Molina. Buenos Aires: Losada.

Jurovietzky, Silvia. 2014. "Poesía y pobreza (Diana Bellessi, Eduardo Mileo y Sergio Raimondi)". VI Congreso Internacional de Letras / 2014. Transformaciones culturales. Debates de la teoría, la crítica y la lingüística: 929-938.

Kesselman, Violeta; Ana Mazzoni \& Damián Selci (comp.). 2012. La tendencia materialista. Antología crítica de la poesía de los 90. Buenos Aires: Paradiso.

Le Lionnais, François. 1990. "Le Troisième secteur". En: La bibliothèque oulipienne, vol. 3. Paris: Seghers. 171-180. 
López, Marcos. 2018. "Serie sub-realismo criollo (2005-2010)", sitio web: http://rolfart. com.ar/artists/marcos-lopez/ (consultado el 04/10/2018).

Ponge, Francis. 1952. "Condición y destino del artista". Sur, 209-210, Buenos Aires (incluido luego en Euvres complètes, t. I, Paris, Gallimard, "Bibliothèque de La Pléiade", 2002).

Porrúa, Ana. 2002. "Todo es historia”, Página/12, Buenos Aires, 29 de diciembre de 2002, Radar.

Porrúa, Ana. 2013. "El lugar de los restos". En: La Habana Elegante. Dallas: Southern Methodist University. 12-22.

Raimondi, Sergio. 2001. Poesía civil, Bahía Blanca: Vox.

Raimondi, Sergio. 2010. Poesia civil, 2da edición. Bahía Blanca: 17grises [Colección Texturas/Literal]. 
